\title{
Assessing knowledge of married women regarding antenatal care
}

\begin{abstract}
Objective: This study aimed to assess knowledge of pregnant women in Gajumata, a rural community of Lahore, regarding the Antenatal care.
\end{abstract}

Methods: Cross-sectional study was conducted among 83 pregnant women from August 2017 to January, 2018. Data was collected using structured questionnaire. Data was entered using Statistical Package for Social Sciences (SPSS) version 21. Descriptive statistics was used to describe the study variables.

Result: When a question was asked if pregnant woman need to go for ANC in response, $(75.9 \%)$ of the participants had knowledge. When participants were asked about ANC in the absence of complication during pregnancy? (74.7\%) of the participants had knowledge regarding this question. When they were asked if there is need of TT vaccine during pregnancy? In response $n=55(66.3 \%)$ said yes they need. The participants were asked about the harmful role of smoking and alcohol for fetus. $74(89.2 \%)$ participants

Conclusion: Overall the participants had good knowledge about the antenatal care during pregnancy

Keywords: antenatal care, knowledge of ANC, pregnant women's' knowledge of ANC, rural community of Lahore
Volume 5 Issue 4 - 2018

\author{
Iffat Ambreen,' Muslim Shah ${ }^{2}$ \\ 'Senior Nursing Instructor, SaidaWaheed FMH College of \\ Nursing, Pakistan \\ ${ }^{2}$ Assistant Professor, Rehman College of Nursing, Rehman \\ Medical Institute, Pakistan
}

Correspondence: Muslim Shah, Assistant Professor, Rehman College of Nursing, Rehman Medical Institute, Pakistan, Email muslimshah266@gmail.com

Received: May 26, 2018| Published: August 03, 2018

\section{Background}

Antenatal Care (ANC), is given diverse meanings by special scholars, along with others the denotation that says, "Antenatal Care means care before birth and includes education, counseling, screening and treatment to monitor and to promote the well - being of the mother and fetus". ${ }^{1}$ In short care that is received by a woman during pregnancy that helps to make sure strong out comes for women and newborn. It is a key doorway point for expectant women to obtain a multiple range of wellbeing services such as nutritional hold up and avoidance or management of anemia; prevention, recognition and treatment of tuberculosis malaria, and sexually transmitted infections. ${ }^{2}$ Antenatal Care is an opening to endorse the reimbursement of skilled presence at birth and to support women to inquire about postpartum care for themselves and their newborn. It is also perfect time to advice women about the profit of child spacing. ${ }^{3}$ Though, Antenatal Care have such smart advantages and strategies, every year, according to the United Nations Millennium Development Goals, half a million girls and women pass away as a consequence of complications throughout pregnancy, the six weeks following delivery or childbirth. $99 \%$ of these deaths occur in developing countries. This show with the intent of the activity of Antenatal care is very pathetic in developing country.

The major reasons that delay the use of Antenatal Care are dissimilar from state to Country. But the reason noticed in developing countries are almost alike such as; hemorrhage, followed by eclampsia, abortion complications, obstructed labor and infection. Added issues are lack of knowledge and attentiveness about reproductive healthiness in the community, family, and health giver. ${ }^{4}$ To ease such factor, Antenatal Care is the mainly central method for detecting pregnancy troubles in the early hours. As Antenatal care is the finest method to diminish maternal mortality, and provide high-quality information for pregnant women regarding their birth and how to avert associated problems. The greatest and mainly benefit of Antenatal Care is to look after the health of women's and their infant as well as signifying the risk signals that will be occurred and requests to be further treated by highly developed health professionals. ${ }^{5}$ A quantity of studies point out that the utilization rate of Antenatal Care is low owing to several factors that require to be examined such as socio demographic factors, Social support knowledge about it. They wrap up that by eliminating these factors it is essential to augment the women's involvement in Antenatal Care.

In Ethiopia, even though, contact to health care services is improving, the nation has faced challenges in growing health care consumption and the percentage of women who deliver in the aid of skilled attendants is the lowest in Sub-Saharan Africa. ${ }^{6}$

\section{Knowledge of women towards ANC care}

Knowledge related to health is measured to be one of the important factors that allow women to be considerate of their right and condition of health in array to look for suitable health services. A Study conducted in diverse part of the world has exposed that level of knowledge regarding ANC in mothers is significant for utilizing ANC service. The knowledge level of expectant mother also varies in deferent component of the globe. A study performed in north central Nigeria which uses institutional based cross sectional survey to examine knowledge and consumption of ANC service has discovered that $87.7 \%$ of women in child bearing age were alert of the payback of antenatal care out of which $25.9 \%$ had light awareness about the actions carried out throughout the antenatal care services, $69.9 \%$ participants had good quality knowledge while $4.2 \%$ mothers had reduced knowledge. ${ }^{7}$ In the same way a study that was carried out in Tunisia to explore mothers' knowledge concerning protective care indicated that $95 \%$ women knew the significance of antenatal assessment. ${ }^{8}$ unlike to these findings a cross-sectional study carry out using two-stage cluster sampling at 24 chosen villages in the District Kham, Nagoya, Japan establish that the majority of the participants $73.9 \%$ short of adequate knowledge about ANC. In Metekel zone another cross-sectional study conducted, North West Ethiopia, 65.6\% of selected women interrogated knew half of the questions regarding knowledge about ANC and so marked as well informed. ${ }^{9}$ 


\section{Methodology}

\section{Study design}

Quantitative Descriptive study design was used in this research to assess the Knowledge of Antenatal Care among Pregnant women at Gajumata Community of Lahore.

\section{Study population}

The population under study were the pregnant women at the Gajumata Community Lahore.

\section{Inclusion criteria}

Pregnant Women with $2^{\text {nd }}$ and Third Trimester of pregnancy

Mothers can read and write English or Urdu.

\section{Sample and sampling}

The sample will be collected through convenient sampling.

i. The sample size was calculated by Slovin's formula. $n=N$ / $1+\mathrm{N}(\mathrm{E})^{2}$

ii. Total population $=105$

iii. Sample size $=83$

\section{Ethical considerations}

This study was held keeping in view all the ethical considerations. Permission was taken from ethical committee of Fatima Memorial Hospital. The Participants were explained the purpose of research and necessary guidance was provided to the participants. A written informed consent was signed by the Participants.

\section{Data collection tool}

A self-administered, self-prepared questionnaire was used to collect the data from the pregnant women. A close ended questionnaire structured with yes, no and don't know was used to collect the data.

\section{Data analysis}

The data was collected and interpreted and then entered into the SPSS version 21 for statistical analysis. The results were analysed in the descriptive methods with the help of graphs and tables showing mean, median modes and frequency and percentages.

\section{Results}

\section{Demographic data}

The above Graph reveals that $\mathrm{n}=9(10.8 \%)$ were less than 20 years, 37 (44.6\%) and $37(44.6 \%)$ were age 21-25 and 26-30 respectively Figure $1 \&$ Figure 2. Looking at the above graphs it shows that $n=14$ (16.9) were Illiterate, $n=37$ (44.6\%) were Primary, $n=24(28.9 \%)$ were having secondary education while, $\mathrm{n}=8(9.6 \%)$ were having graduation and above. The above graph highlights that $\mathrm{n}=49(59 \%)$ were in $2^{\text {nd }}$ trimester while remaining $\mathrm{n}=34(41 \%)$ participants were in $3^{\text {rd }}$ trimester and trimester one was excluded Figure 3.

\section{Descriptive result findings}

When a question was asked if pregnant woman need to go for ANC? The results are presented in above graph which shows that $\mathrm{n}=63(75.9 \%)$ responded Yes, $\mathrm{n}=8(9.6 \%)$ Responded with no and $\mathrm{n}=12(14.5 \%)$ said that they don't know Figure $4 \&$ Figure 5. On a question is it required to go for $\mathrm{ANC}$ even if there is no complication during pregnancy? The results were recorded in the above graph $\mathrm{n}=62$ $(74.7 \%)$ responded said Yes, $n=4(94.8 \%)$ Responded said no and $\mathrm{n}=17(20.5 \%)$ participants said that they don't know On a question that there must be planned schedule of Antenatal Care visit according to trimesters the following results were found. The results reveals that $\mathrm{n}=20(24.1 \%)$ said that yes it should be, $\mathrm{n}=25(30.1 \%)$ said that there should be no regular visits, and $n=38(45.8 \%)$ said that they don't know about routine schedule visits Figure 6.

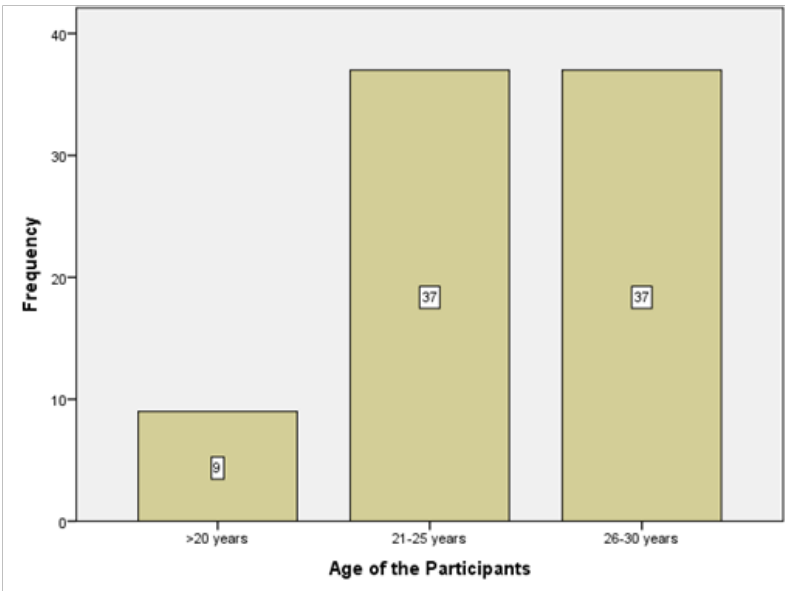

Figure I Age of participants.

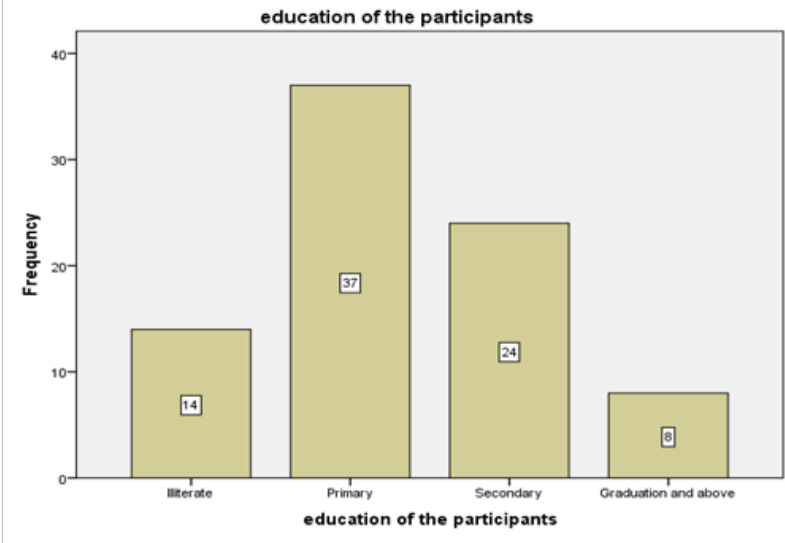

Figure 2 Education of the participants.

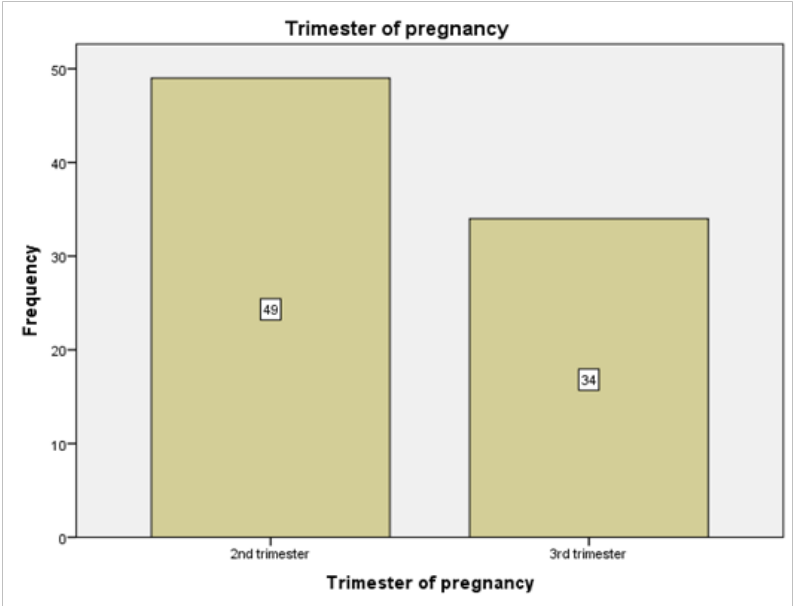

Figure 3 Trimester of pregnancy. 


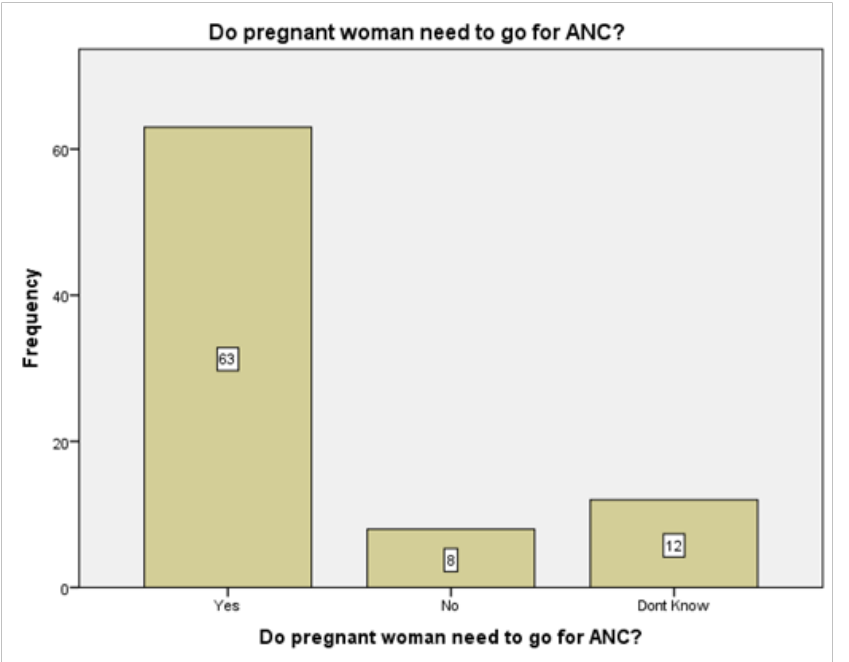

Figure 4 Do pregnant woman need to go for ANC?.

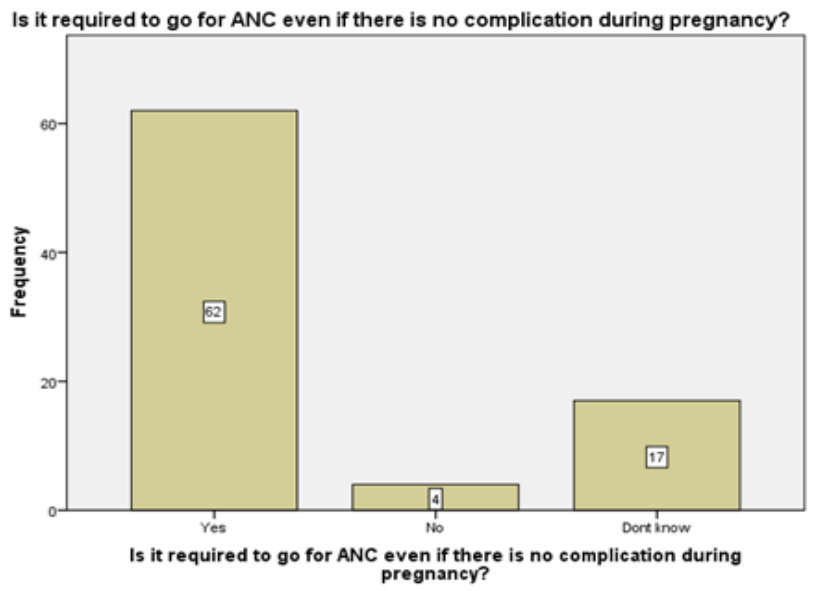

Figure $\mathbf{5}$ is it required to go for ANC even if there is no complication during pregnancy?.

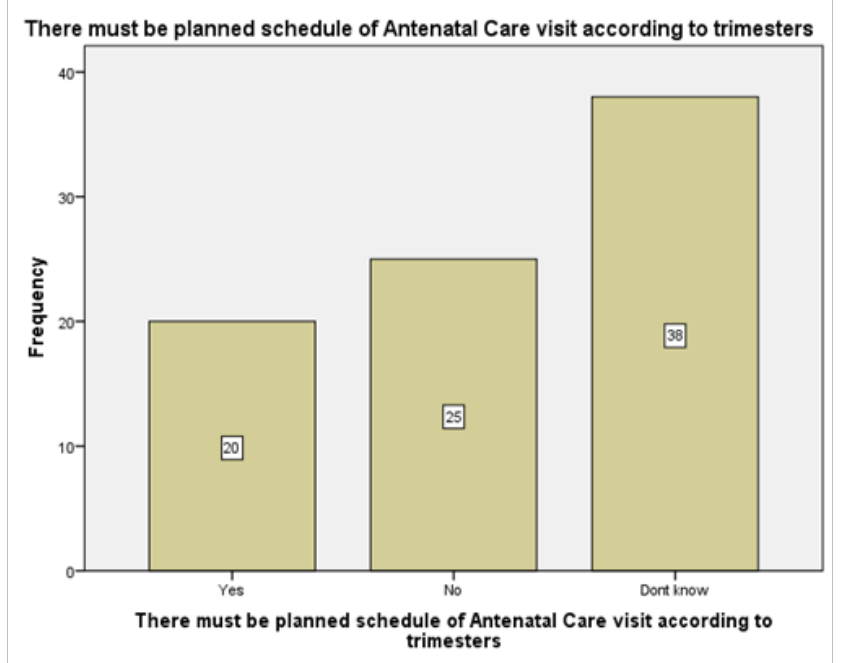

Figure 6 There must be planned schedule of antenatal care visit according to trimesters.
The participants were asked if there is need of TT vaccine during pregnancy. In response $n=55(66.3 \%)$ responded Yes, $n=8(9.6 \%)$ Responded with no and $n=20(24.1 \%)$ said that they don't knows shown in the above graph Figure $7 \&$ Table 1.

Table I Two TT injection should be injected during pregnancy

\begin{tabular}{llllll}
\hline & Frequency & Percent & $\begin{array}{l}\text { Valid } \\
\text { percent }\end{array}$ & $\begin{array}{l}\text { Cumulative } \\
\text { percent }\end{array}$ \\
\hline Yes & 45 & 54.2 & 54.2 & 54.2 \\
No & 17 & 20.5 & 20.5 & 74.7 \\
& $\begin{array}{l}\text { Non't } \\
\text { know } \\
\text { Total }\end{array}$ & 21 & 25.3 & 25.3 & 100 \\
\hline
\end{tabular}

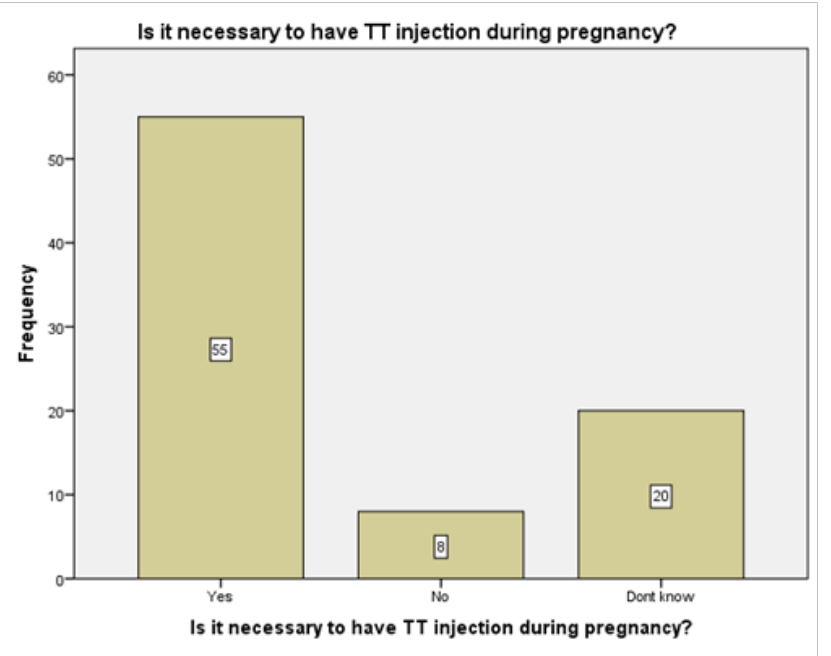

Figure $\mathbf{7}$ Is it necessary to have TT injection during pregnancy?.

When the participants were asked if 2 doses of TT injection are recommended in first pregnancy, the results were as below. From the participants $\mathrm{n}=45(54.2 \%)$ said that Yes two doses, $\mathrm{n}=17(20.5 \%)$ Responded with no and $n=21(25.3 \%)$ said that they don't know about the number of TT doses as shown in the above table Figure 8.

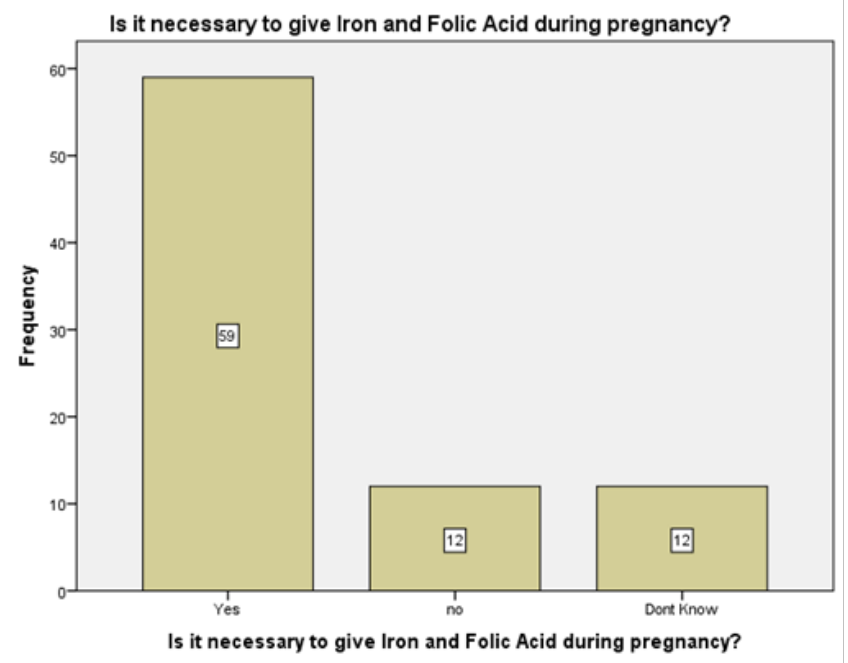

Figure 8 Is it necessary to give Iron and Folic acid during pregnancy?. 
The participants were asked about the need of Iron and Folic acid use during pregnancy on which the participants replied as under. Among the participants $\mathrm{n}=59(79 \%)$ said that Yes it is necessary, $\mathrm{n}=12(14.5 \%)$ know that iron and folic acid are not needed and $\mathrm{n}=12$ (14.5\%) said that they don't know Table 2.

Table 2 Iron and folic Acid is necessary for fetal growth during Pregnancy

\begin{tabular}{|c|c|c|c|c|c|}
\hline & & Frequency & Percent & $\begin{array}{l}\text { Valid } \\
\text { percent }\end{array}$ & $\begin{array}{l}\text { Cumulative } \\
\text { percent }\end{array}$ \\
\hline & Yes & 50 & 60.2 & 60.2 & 60.2 \\
\hline \multirow{3}{*}{ Valid } & No & 16 & 19.3 & 19.3 & 79.5 \\
\hline & $\begin{array}{l}\text { Don't } \\
\text { Know }\end{array}$ & 17 & 20.5 & 20.5 & 100 \\
\hline & Total & 83 & 100 & 100 & \\
\hline
\end{tabular}

The results of above table shows that $n=50(60.2 \%)$ responded Yes that Iron and Folic acid are necessary for fetal growth and development, $\mathrm{n}=16$ (19.3\%) Responded with no and $\mathrm{n}=17$ (20.5\%) said that they don't know about Folic acid and iron role in fetal growth Figure 9. The participants were asked about the harmful role of smoking and alcohol for fetus. 74 (89.2\%) participants replied that it is harmful, $n=4(4.8 \%)$ Responded with no and $n=5(6 \%)$ said that they don't know the harmful role of smoking and alcohol use in pregnancy Figure 10.

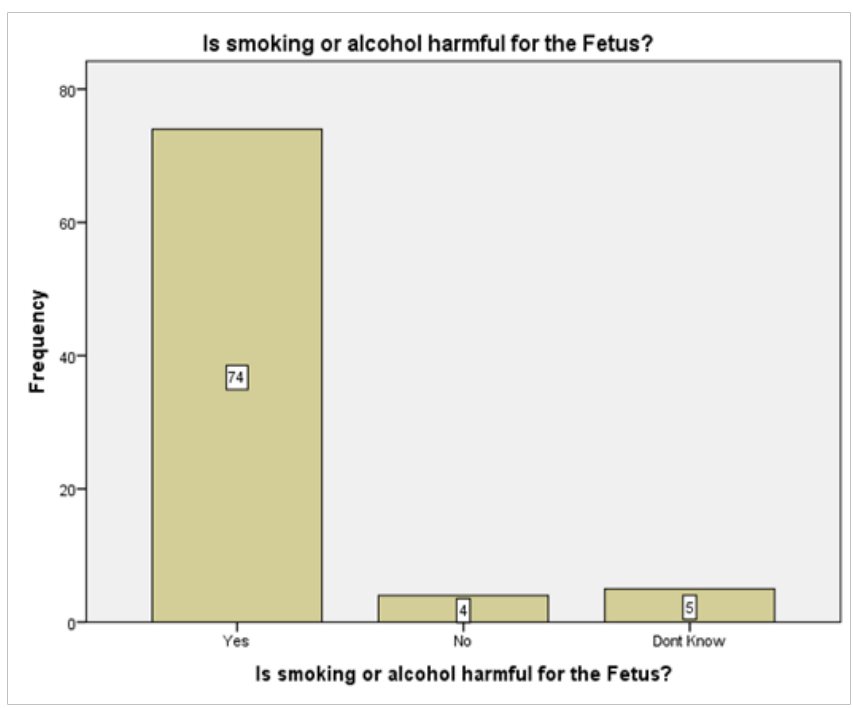

Figure 9 Is smoking or alcohol harmful for the fetus.

The participants were asked if pregnant women need extra nutrition, majority $n=62(74.7 \%)$ replied that yes they need, $n=8$ $(9.6 \%)$ Responded know that they don't need and $n=13(1.7 \%)$ said that they don't know about the nutritional requirement in pregnancy Figure 11. When a question was asked if the hospital are the ideal place for delivery. The results are presented in above graph which shows that $\mathrm{n}=58(69.9 \%)$ responded Yes, $\mathrm{n}=12(14.5 \%)$ Responded with no and $n=13(15.7 \%)$ said that they don't know Figure 12. The above graph reveals that $\mathrm{n}=25(30.1 \%)$ participants believe that breast feeding should be started in first 24 hours, $\mathrm{n}=50(60.2 \%)$ said that no it should be started after 24 hours while $n=8(9.6 \%)$ said that they don't know about it.

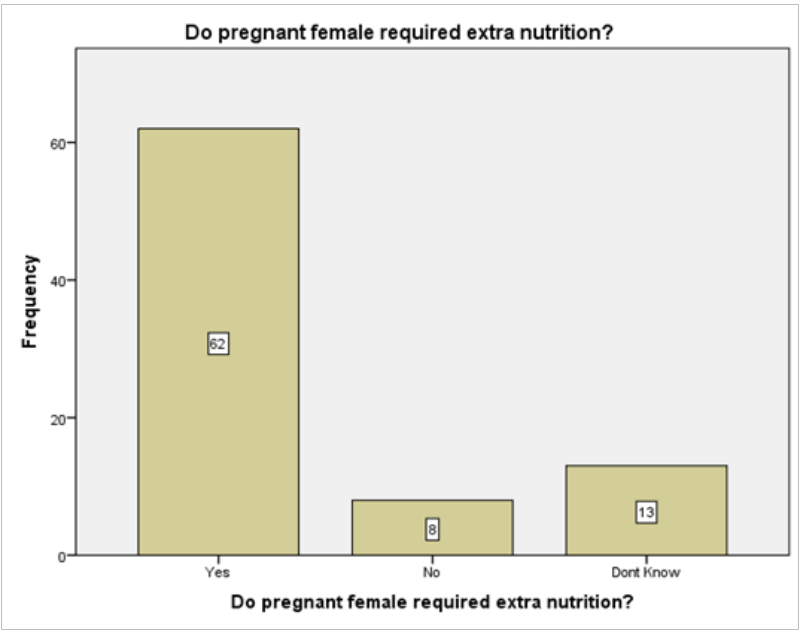

Figure I0 Do pregnant female required extra nutrition.

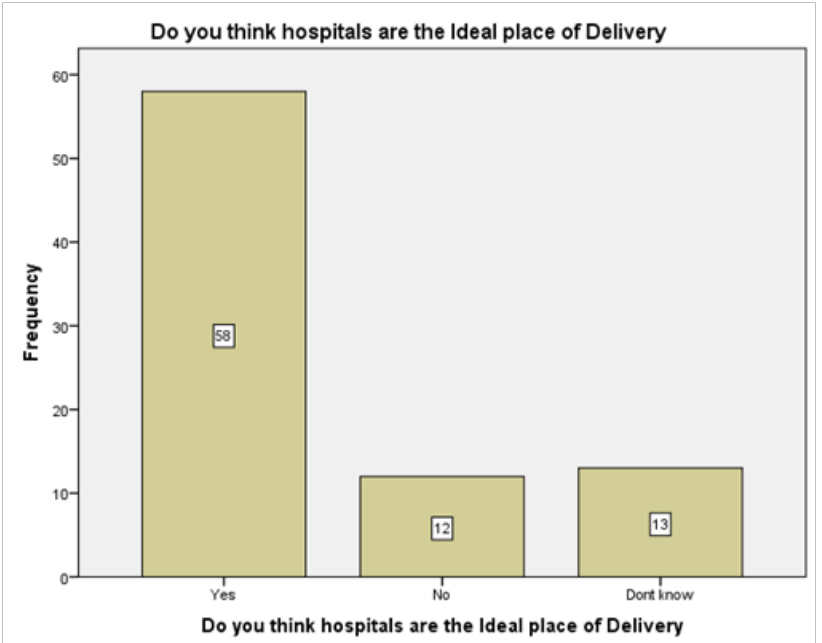

Figure I I Do you think hospitals are the ideal place of delivery.

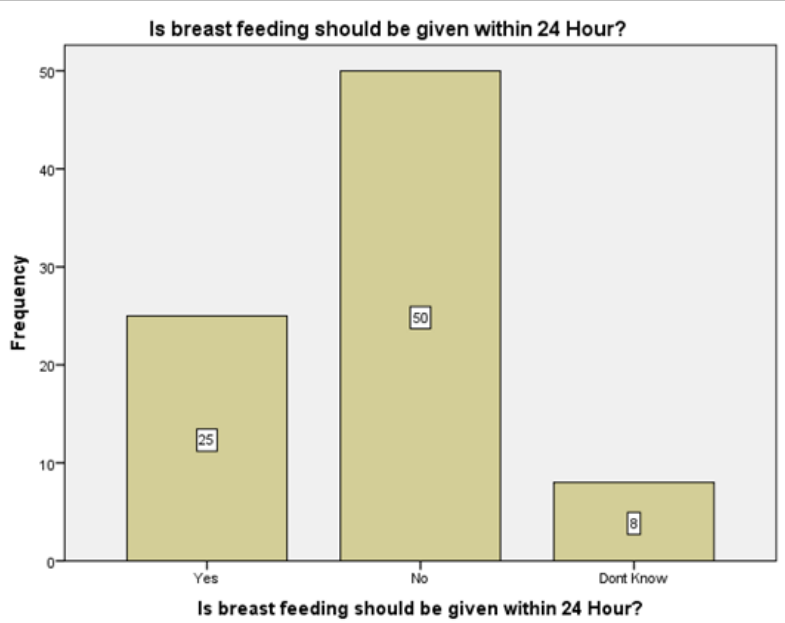

Figure 12 Is breast feeding should be given within 24 hours?. 


\section{Discussion}

This study exposed that bulk of the participants has good quality knowledge concerning the antenatal care. This outcome is almost analogous with cross-sectional study carried out in Metekel zone, North West Ethiopia, in which $65.6 \%$ of participant women question knew half of the knowledge questions on ANC and accordingly marked as knowledgeable. ${ }^{10}$ This result was advanced than outcome of study completed by Yang, Yoshitoku and his colic's, in Khan District, Xiengkhouang province Nagoya, Japan, shapeing that occurrence of good knowledge amongst mothers who received ANC care in person $45.5 \% .{ }^{11}$ The mothers were inquired if pregnant women require additional nutrition, majority $\mathrm{n}=62(74.7 \%)$ respond that yes they require, $\mathrm{n}=8(9.6 \%)$ answer know that they don't want and $n=13(1.7 \%)$ thought that they don't be familiar with the nutritional necessities in pregnancy. likewise incidence of good knowledge was lesser $44.2 \%$ in Jempol, Nigeria Semilan. In one more our hand result was lower than study done in South-West Nigeria in which above all knowledge was reported to be $74.6 \%$. And once more a different study from north central Nigeria reported good knowledge of $69.9 \%{ }^{12-14}$

\section{Conclusion}

According to this research bulk of the women were originate to have good Knowledge of ANC and somewhat better than half of the participant had well believe of ANC. Their knowledge on definite feature of antenatal care was still deprived. Together women who have spouse support had elevated likely hood of having good knowledge and approach. Contrast to women with educational status better than secondary schools those with fewer than elementary school was less likely to have high-quality attitude. And as well women who visit health facility for ANC throughout her nearly all recent pregnancy were less expected to have good quality attitude. 34

\section{Limitations}

Small sample size, the study findings could not be generalized.

\section{Acknowledgments}

None.

\section{Conflict of interest}

The author declares that there is no conflict of interest.

\section{References}

1. Adewoye K, Musa I, Atoyebi O, et al. Knowledge and utilization of antenatal care services by women of child bearing age in Ilorin-East local government area, North Central Nigeria. International journal of science and technology. 2013;3(3):188-189.
2. Berhe KK, Welearegay HG, Abera GB, et al. Assessment of antenatal care utilization and its associated factors among 15 to 49 years of age women in Ayder Kebelle, Mekelle City 2012/2013; a cross sectional study. Open Journal of Advanced Drug Delivery. 2014;2(1):62-75.

3. Wilunda C, Quaglio G, Putoto G, et al. Determinants of utilisation of antenatal care and skilled birth attendant at delivery in South West Shoa Zone, Ethiopia: a cross sectional study. Reproductive health. 2015;12(1):74.

4. Tew M. Safer childbirth?: a critical history of maternity care. Springer. 2013.

5. Finer LB, Zolna MR. Declines in unintended pregnancy in the United States, 2008-2011. New England Journal of Medicine. 2016;71(7):843852 .

6. Sonko A, Worku A. Prevalence and predictors of exclusive breastfeeding for the first six months of life among women in Halaba special woreda, Southern Nations, Nationalities and Peoples' Region/SNNPR/, Ethiopia: a community based cross-sectional study. Arch Public Health. 2015;73(1):53.

7. Igbokwe C. Knowledge and attitude of pregnant women towardsantenatal services in Nsukka local government area of Enugu state, Nigeria. Journal of Research in Education and Society. 2012;3(1).

8. Maputle M, Lebese R, Khoza L, et al. Knowledge and attitudes of pregnant women towards antenatal care services at Tshino Village, Vhembe district, South Africa. African Journal for Physical Health Education. 2013;19:126-137.

9. Swamy GK, Beigi RH. Maternal benefits of immunization during pregnancy. Vaccine.2015;33(47):6436-6440.

10. Demographic E. Health survey: Addis Ababa. Ethiopia and Calverton, Maryland, USA: central statistics agency;2011.

11. Organization WH. World health statistics 2015: World Health Organization. 2015.

12. Rahman A, Kumarathasan P, Gomes J. Infant and mother related outcomes from exposure to metals with endocrine disrupting properties during pregnancy. Science of the Total Environment. 2016;569:10221031.

13. Salisbury P, Hall L, Kulkus S, et al. Family planning knowledge, attitudes and practices in refugee and migrant pregnant and post-partum women on the Thailand-Myanmar border-a mixed methods study. Reproductive health.2016;13(1):94.

14. Schoenmakers I, Pettifor JM, Peña-Rosas JP, et al. Prevention and consequences of vitamin D deficiency in pregnant and lactating women and children: A symposium to prioritise vitamin D on the global agenda. J Steroid Biochem Mol Biol. 2016;164:156-160. 